\title{
Parental work hours and household income as determinants of unhealthy food and beverage intake in young Australian children
}

\author{
Chelsea E Mauch ${ }^{1,2, *}{ }^{(0)}$, Thomas P Wycherley ${ }^{3}$, Lucinda K Bell ${ }^{1}\left(\mathbb{D}\right.$, Rachel A Laws ${ }^{2,4}$, \\ Rebecca Byrne ${ }^{2,5}$ and Rebecca K Golley ${ }^{1,2}$ \\ ${ }^{1}$ Caring Futures Institute, College of Nursing and Health Sciences, Level 7, SAHMRI building, North Terrace, Flinders \\ University, Adelaide, SA 5000, Australia: ${ }^{2}$ Early Prevention of Obesity in Childhood Centre of Research Excellence, \\ Sydney, Australia: ${ }^{3}$ Alliance for Research in Exercise, Nutrition and Activity, Allied Health and Human Performance, \\ University of South Australia, Adelaide, Australia: ${ }^{4}$ Institute for Physical Activity and Nutrition, School of Exercise and \\ Nutrition Science, Deakin University, Melbourne, Australia: ${ }^{5}$ Queensland University of Technology, School of Exercise \\ and Nutrition Sciences, Faculty of Health, Centre for Children's Health Research, South Brisbane, Australia
}

Submitted 17 March 2021: Final revision received 3 February 2022: Accepted 5 February 2022: First published online 9 February 2022

\begin{abstract}
Objective: This study examined parental work hours and household income as determinants of discretionary (energy-dense, nutrient-poor) food and beverage intake in young children, including differences by eating occasion.

Design: Secondary analysis of cross-sectional data. Three hierarchical regression models were conducted with percentage of energy from discretionary food and beverages across the day, at main meals and at snack times being the outcomes. Dietary intake was assessed by $1 \times 24-\mathrm{h}$ recall and $1-2 \times 24-\mathrm{h}$ food record(s). Both maternal and paternal work hours were included, along with total household income. Covariates included household, parent and child factors.

Setting: Data from the NOURISH/South Australian Infants Dietary Intake studies were collected between 2008 and 2013.

Participants: Participants included 526 mother-child dyads (median (interquartile range) child age $1.99(1.96,2.03)$ years). Forty-one percentage of mothers did not work while $57 \%$ of fathers worked $35-40$ h/week. Most (85\%) households had an income of $\geq \$ 50 \mathrm{k}$ AUD/year.

Results: Household income was consistently inversely associated with discretionary energy intake $(\beta=-0 \cdot 12$ to $-0 \cdot 15)$. Maternal part-time employment (21-35 h/ week) predicted child consumption of discretionary energy at main meals $(\beta=0.10, P=0.04)$. Paternal unemployment predicted a lower proportion of discretionary energy at snacks $(\beta=-0.09, P=0.047)$.

Conclusions: This work suggests that household income should be addressed as a key opportunity-related barrier to healthy food provision in families of young children. Strategies to reduce the time burden of healthy main meal provision may be required in families where mothers juggle longer part-time working hours with caregiving and domestic duties. The need to consider the role of fathers and other parents/caregivers in shaping children's intake was also highlighted.
\end{abstract}

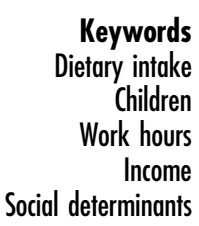

Excess intakes of energy-dense, nutrient-poor foods and beverages are typical of modern, global dietary patterns $^{(1-3)}$. This is contributing to the high rates of obesity and non-communicable diseases such as CVD and diabetes ${ }^{(4)}$. Termed 'discretionary' foods and beverages in Australia $^{(5)}$, the mean intake of energy-dense, nutrientpoor foods and beverages amongst adults was more than twice the recommended maximum daily serves in 2011$2012^{(6)}$. Similarly, the 2001-2003 National Health and Nutrition Examination Survey data from the USA found that $96 \%$ of adults consumed excessive energy from solid fats, added sugars and alcohol ${ }^{(2)}$. Furthermore, the consumption of excess discretionary foods and beverages begins from as early as the second year of life ${ }^{(1,2,7)}$ and increases 
over time ${ }^{(7)}$. As the early years are critical in the development of food preferences ${ }^{(8)}$, addressing the early intake of discretionary foods and beverages may prevent unhealthy dietary intake in adulthood.

The determinants of dietary intake are broad, including factors at the individual, household and community levels ${ }^{(9,10)}$. Figure 1 outlines child, parent and household-level factors and their proposed relationship with children's intake of discretionary foods and beverages and was adapted from similar models of the home and family food environment ${ }^{(10,11)}$. Some of these relationships are well supported by research in young children, such as the role of child eating behaviours ${ }^{(12,13)}$ and parental feeding practices $^{(14)}$, while less is understood about the role of family or household-level factors as determinants of young children's discretionary food and beverage intake. Innate food preferences and child eating behaviours play a key role in children's acceptance of food and beverages ${ }^{(8,15)}$. However, child preferences and behaviours are set amongst, and shaped by, the home food environment, which includes the resources, structures and behaviours leading to the availability and provision of food to children ${ }^{(10)}$. Parental and household factors such as parental intake and the availability and accessibility of food are strong, consistent determinants of child dietary intake ${ }^{(16)}$. Therefore, parents are commonly targeted as key agents of change in interventions addressing the dietary intake of young children ${ }^{(17)}$.

According to the COM-B framework of behaviour, a combination of capability (C), opportunity (O) and motivation $(\mathrm{M})$ is required in order to perform a behaviour ${ }^{(18)}$. For example, the behaviour 'parental food provision' requires nutrition and food knowledge, and cooking skills (capability), a desire, intention or habits that facilitate healthy food provision (motivation) and adequate time, money and other resources to plan, purchase and prepare healthy food and meals (opportunity). Interventions to reduce children's discretionary food and beverage intake have mainly focused on parental capability and motivation, targeting factors such as child eating behaviour, parental feeding practices, nutrition knowledge and cooking skills, and self-efficacy ${ }^{(19-23)}$. The impact of interventions to reduce young children's intake of discretionary foods and beverages has so far been modest, suggesting a need to expand this focus to encompass opportunity-related determinants of young children's dietary intake ${ }^{(21)}$.

Time and money are important determinants of healthy dietary intake in adults ${ }^{(24)}$. Research in school-age children provides evidence of the role of these determinants with respect to discretionary food and beverage intake. A cross-sectional study with 9-13-year-old Australian children found that attitudes, self-efficacy, parental feeding

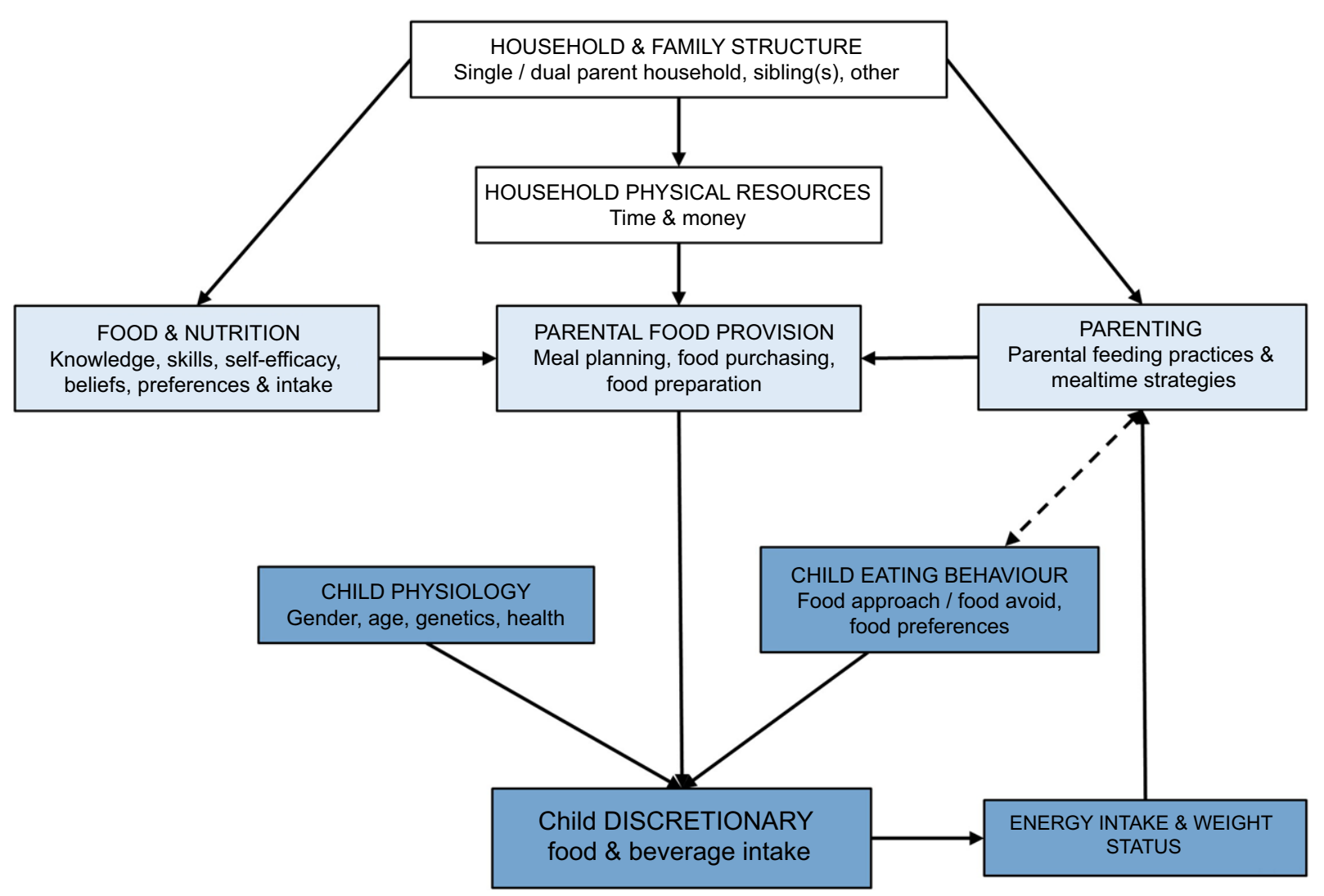

Fig. 1 Conceptual model of determinants of young children's discretionary food and beverage intake, with child factors in dark blue, parent factors in light blue and external family/household factors in white 
practices and home food availability were important determinants of discretionary food and beverage intake ${ }^{(25)}$. Markers of socio-economic position, such as maternal education, income and employment, moderated the relationship between determinants and intake. Furthermore, the amount of time mothers spent in employment seemed to be more important than maternal occupation ${ }^{(25)}$. These findings suggest that parental work hours and household income play an important role in the discretionary food and beverage intake of school-age children. Their role as determinants of young children's intake is yet to be investigated however and may be different due to variations in parental influence on child dietary intake over the life course $^{(26)}$.

The time and money required for the provision of food may not be consistent across eating occasions. In Australia, the typical eating pattern consists of three main meals, namely breakfast, lunch and the evening meal, and in young children, close to three snacks per $\mathrm{d}^{(27)}$. The food and beverages consumed at these eating occasions differ ${ }^{(27,28)}$. For example, snacks commonly feature ready-to-eat foods such as sweet biscuits and salty snacks, which require minimal preparation ${ }^{(27,28)}$, whereas the evening meal which traditionally incorporates meat, vegetables and grains ${ }^{(28)}$ may take more time to plan, purchase and prepare. Qualitative evidence suggests that main meals are more time intensive to provide, with low-income employed parents citing time scarcity as a key barrier to healthy evening meal provision ${ }^{(29,30)}$. The purchase of fast food after a day at work has been described as a response to time scarcity ${ }^{(29)}$, whereas in a discrete choice experiment, time and money were not found to be important to parents in the selection of snacks for their 3-7-year-old children compared with the influence of child resistance and co-parent support $^{(31)}$. Sub-group analyses found that cost was more important to parents living in lower socio-economic areas, compared with those living in higher socio-economic areas ${ }^{(31)}$. Differences in the determinants of intake across eating occasions would warrant the tailoring of intervention strategies to meal type, although quantitative evidence is required to support this.

This study aimed to examine parental work hours and household income as determinants of discretionary food and beverage intake in young children, and whether their influence differs according to eating occasion. This study will provide evidence regarding opportunity-related determinants of young children's intake of discretionary foods and beverages, supporting the development of intervention strategies covering all aspects of the COM-B framework $^{(18)}$. Finally, the exploration of the role of parental work hours and household income on young children's discretionary food and beverage intake at different eating occasions will support more targeted and potentially effective intervention strategies.

\section{Methods}

\section{Study design, setting and sample}

This study was a secondary analysis of cross-sectional data collected as part of the NOURISH and South Australian Infants Dietary Intake studies, conducted in South Australia and Queensland, Australia, between 2008 and 2013. The Strengthening the Reporting of Observational Studies in Epidemiology-Nutritional Epidemiology (STROBE-nut) statement guides study reporting ${ }^{(32)}$. Recruitment and data collection procedures for both studies have been described in detail previously ${ }^{(22,33)}$. Participants included mother-child dyads, where the infant was born at term with no condition or abnormality affecting development or feeding behaviour, and the mother had facility with the English language. NOURISH participants were randomised to receive a feeding intervention promoting positive infant and toddler feeding practices and the development of healthy food preferences, or usual care. Both NOURISH intervention and control participants were included in the present work. South Australian Infants Dietary Intake participants were recruited at the same time and methodology as per the NOURISH control arm. Both cohorts were followed up over the course of 5 years at various ages.

\section{Data collection}

Parent-completed surveys were administered to the same cohort at infant birth, 4-6 months and 2 years and covered parent-reported infant feeding and parenting practices, and maternal and family demographics. The parent involved in data collection was the mother, except $n 1$, where maternal data were provided at all time points except 2 years where the father became the primary carer. Data collected at infant birth included child gender, maternal age and parental educational attainment. Infant and maternal anthropometrics were measured by study staff. Maternal BMI $\left(\mathrm{kg} / \mathrm{m}^{2}\right)$ was calculated from weight and height data collected at child aged 4-6 months. All other data were collected at child aged 2 years. Child BMI Z-score was calculated using child weight and height measured according to a standardised protocol and the WHO Anthro version 3.0.1 and macros programme (Department of Nutrition for Health and Development, World Health Organization) ${ }^{(34,35)}$.

One 24-h recall and two 24-h food records were conducted with the primary caregiver at child aged 2 years for the collection of child dietary intake data ${ }^{(22)}$. Participants with 2-3 d of intake data were included ${ }^{(36)}$. The 24-h recall utilised a standardised three-pass protocol conducted by trained dietitians via telephone. Food recall and record data included time of consumption, a description of the food and the quantity consumed. Where a primary caregiver felt they could not accurately recall their child's intake on the day prior, the recall was attempted 
(unannounced) on another day. An additional food record booklet was provided to be used when the child was being cared for by someone other than the primary caregiver.

\section{Survey data preparation}

Multiple-choice questions, including education, household income, other children and marital status, were collapsed to create dichotomous variables (i.e. university educated $v$. not university educated, less than $\$ 50000 \mathrm{v} . \$ 50000$ or more, single child $v$. multiple child housebold, partnered $v$. not partnered). Categories were based on the distribution of the data, whilst ensuring they were meaningful (i.e. University education being considered a high level of educational attainment, and less than $\$ 50 \mathrm{k}$ AUD being considered low income for a family at the time) $)^{(37)}$. As past research has found non-linear relationships between maternal work hours and children's weight and weightrelated outcomes ${ }^{(26,38)}$, work hours were grouped into categories and dummy coded for analysis. Maternal working hours (paid employment only) were grouped into four categories, including: not working (reference category), working 1 to $<21 \mathrm{~b}, 21$ to $<35 \mathrm{~b}$ and $35 \mathrm{~b}$ or more per week. Paternal working hours (paid employment only) were grouped differently to account for differences in the spread of working hours amongst fathers: not working, working $1-<35 \mathrm{~b}, 35-40 \mathrm{~b}$ (reference category) and greater than $40 \mathrm{~b} /$ week.

Thirty-five Child Eating Behaviour Questionnaire items were used to calculate scores for four sub-scales of 'food approach' (food responsiveness, emotional over-eating, enjoyment of food and desire to drink) and four of 'food avoid' (satiety responsiveness, slowness in eating, emotional under-eating and food fussiness) eating behaviours $^{(15)}$. The internal validity and test-retest reliability of these sub-scales have been established in prior research $^{(15,39)}$. Satiety responsiveness and slowness in eating were combined into a single score as they have been shown to be highly correlated ${ }^{(39)}$. Mean scores were calculated for the remaining sub-scales, with scores between 1 and 5 indicating low to high levels of each eating behaviour.

Items and sub-scales from the Feeding Practices and Structure Questionnaire represented parental feeding practices $^{(40)}$. Predictive validity has been demonstrated against Child Eating Behaviour Questionnaire sub-scales, and internal reliability demonstrated with Cronbach's $\alpha$ values between 0.61 and $0 \cdot 87^{(40)}$. Four of the seven sub-scales were included in the present research, namely reward for behaviour, reward for eating, covert restriction and overt restriction, along with a single item to assess family meal setting ${ }^{(40)}$.

Nine ( $1.7 \%$ of 544 ) participants had missing data on five or more variables and another nine were missing data that were not at random ( $1.7 \%$ of 544$)$; all eighteen were therefore excluded from the regression analyses. Of the remaining participants ( $n 526)$, six $(1 \cdot 1 \%)$ had missing data for two variables and sixty-two (11.8\%) for one, which were imputed using maximum likelihood estimation. Descriptive statistics were undertaken on the original sample of 544 (with missing data) and on the sample of 526 with imputed data and were found to be similar.

\section{Dietary intake data preparation}

Food intake data were entered into FoodWorks Professional Version 9 (Xyris Software Pty Ltd), using energy and nutrient data from the 2007 AUSNUT database $^{(41)}$. Data were exported into SPSS Version 22 (IBM) and merged with 8-digit food codes from the AUSNUT 2007 database. Discretionary foods and beverages were identified using the Australian Bureau of Statistics discretionary food flag ${ }^{(42)}$. Discretionary foods and beverages are defined as those that are not essential for meeting nutrient requirements and are generally energy dense, higher in saturated fat, added sugars, $\mathrm{Na}$ and/or alcohol and low in fibre ${ }^{(5)}$. Data were cleaned according to a standard protocol ${ }^{(22)}$.

Defined time periods were used to categorise food and beverage intake into eating occasions ${ }^{(27,43)}$, with all food and beverages consumed during these time periods representing main meals and snacks. The time periods were constructed by plotting the energy content of eating occasions across the day for the whole sample to observe when peaks in intake occurred. Main meals included foods and beverages consumed between 06.00-08.59 hours (breakfast), 11.30-14.29 hours (lunch) and 17.00-19.59 hours (evening meal), while snacks included all food and beverages consumed outside of these times. Foods or meals with no time of consumption recorded were excluded from analysis (18/544 (3.3\%) participants with dietary data, a mean (SD) of 654 (484) kJ per participant).

\section{Data analysis}

Analyses were conducted in SPSS version 25 (IBM). Total intake of energy (kilojoules) from discretionary foods and beverages, and discretionary energy consumed at main meals and snacks, was calculated separately for each day of intake and averaged across the number of days reported ( $n 2$ or 3 ). Descriptive statistics for socio-demographic and intake data included medians and interquartile range for continuous variables and counts and percentages for categorical data. Three hierarchical regression models were conducted with the proportion of total energy consumed from discretionary foods and beverages, and the proportion consumed at main meals and snacks. Variables (total of twenty-nine) were entered in six steps, starting with variables representing: (1) parental work hours (six variables) and household income, followed by; (2) household factors (relationship status, highest level of paternal education and number of children in the household); (3) maternal factors (highest level of maternal 
education, maternal age at infant birth, maternal BMI); (4) parental feeding practices (reward for behaviour, reward for eating, covert restriction, overt restriction, same food as rest of family and intervention condition); (5) child factors (child gender, child BMI $Z$-score and child age) and (6) child eating behaviours (food responsiveness, enjoyment of food, satiety responsiveness/slowness in eating, food fussiness, emotional overeating, emotional undereating and desire to drink). Intervention condition was included in the parental feeding practices step, as the intervention focused on directly addressing these practices. The sample size of 526 allowed for eighteen cases per variable, meeting most sample per variable recommendations for regression analyses ${ }^{(44)}$. There was no multicollinearity, assessed by correlations, tolerance values and variance inflation factor values. Unstandardised beta $(\beta)$, standard error for the unstandardised beta (SE), standardised beta $(\beta)$ and adjusted $R^{2}$ values are presented. Statistical significance was set at $P \leq 0.05$.

\section{Results}

Figure 2 describes the study participants, and Table 1 presents demographic information for the maximum available sample at child aged 2 years. Seven hundred and nineteen participants provided some data at 2 years, with 654 providing survey data. Mothers were mostly partnered (95\%, $n$ 618/654) with a household income over $\$ 50000$ AUD per year $(82 \%, n$ 518/631). Just over half were university educated $(58 \%, n 417 / 716)$ and less than half ( $43 \%, n$ 275/639) were not working, while fathers

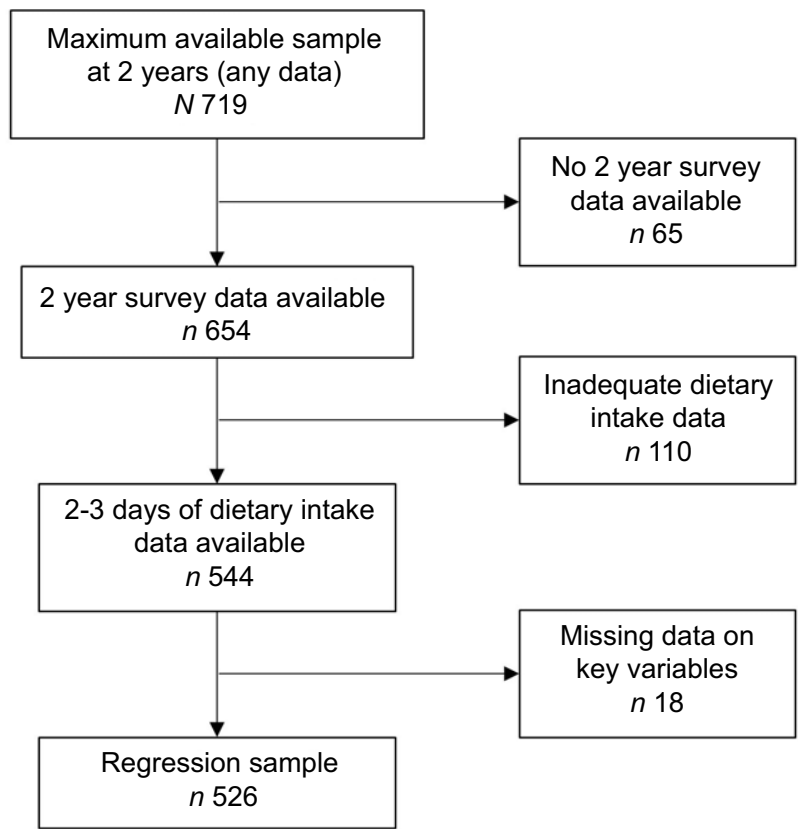

Fig. 2 Study participants based on survey and dietary intake data availability were mostly working full time ( $82 \%, n$ 525/640). Participants retained at the 2 -year data collection point were older and more likely to hold university qualifications compared with the maximum available sample at baseline (data published elsewhere) ${ }^{(45)}$. Five hundred and forty-four children had 2 ( $n$ 10) or 3 ( $n$ 534) days of dietary intake data, of which eighteen were excluded from the regression analyses due to missing data, resulting in a final sample size of 526. Compared with the maximum available sample, the regression sample ( $n$ 526) included mothers who were slightly older (median (interquartile range) 32 (28-35) years $v$. 31 (28-35) years), more likely to be partnered ( $n$ 513/526, $98 \%$ v. $n$ 618/654, $94 \%$ ), university educated $(325 / 526,62 \% v \cdot 417 / 716,58 \%)$ and of a higher income $(449 / 526,85 \% v$. 518/631, 82\%). Discretionary foods and beverages contributed almost one-fifth of children's total daily energy intake (19.6\%). Main meals contributed a larger overall proportion of energy intake from discretionary foods and beverages than snacks (554 (313-856) kJ compared with $313(146-522) \mathrm{kJ}$ ).

The final regression models (after all six steps) investigating the relationship between parental work hours, household income and children's discretionary food and beverage intake are presented in Table 2. Household income showed a consistent, inverse relationship with children's discretionary food and beverage intake across all three models $(\beta=-0.15, P=0.002 ; \beta=-0.12, P=0.02$ and $\beta=-0 \cdot 13, P=0 \cdot 01$ for total discretionary energy intake at main meals and snacks combined, at main meals only and at snacks only, respectively). Children of families with a gross household income below \$50 000 AUD/year consumed significantly more energy from discretionary foods and beverages (irrespective of eating occasion) than those with household incomes of \$50 000 AUD/year or more.

Maternal work hours contributed significantly to the total and main meal models, after controlling for covariates (see online supplementary material, Supplemental Tables 1 and 2). Children with mothers working 21-35 h/week consumed significantly more total energy from discretionary foods and beverages $(\beta=0.11, P=0.03)$ and at main meals $(\beta=0 \cdot 10, P=0.04)$ than children with mothers who were not working (reference group), whereas children with fathers working greater than $40 \mathrm{~h} /$ week had a lower intake of discretionary foods and beverages at main meals $(\beta=-0 \cdot 11, P=0 \cdot 01)$, compared with their peers with fathers working a standard full-time week of 35-40 h. This was independent of paternal education and household income, both of which were also inversely associated with discretionary intake at main meals $(\beta=-0 \cdot 12, P=0 \cdot 01$ and $\beta=-0 \cdot 12, P=0 \cdot 02$, respectively).

Although maternal work hours were not associated with the intake of discretionary foods and beverages at snacks, children with fathers not working consumed less discretionary foods and beverages at snacks $(\beta=-0.09$, $P=0.047)$. The association between snack discretionary intake with paternal education was the opposite of that 
Table 1 Child, parental and household characteristics of the maximum sample at child aged 2 years $(n 719)$ and regression sample $(n 526)$

\begin{tabular}{|c|c|c|c|c|c|c|}
\hline \multirow[b]{2}{*}{ Characteristic } & \multirow[b]{2}{*}{ Categories } & \multirow[b]{2}{*}{$n$} & \multicolumn{2}{|c|}{ Maximum available sample* } & \multicolumn{2}{|c|}{ Regression sample† ( $n$ 526) } \\
\hline & & & $n$ or median & $\%$ or IQR & $n$ or median & $\%$ or IQR \\
\hline \multicolumn{7}{|l|}{ Child variables } \\
\hline \multirow[t]{2}{*}{ Child gender } & Male & 716 & 338 & 47 & 240 & 46 \\
\hline & Female & & 378 & 53 & 286 & 54 \\
\hline \multicolumn{2}{|l|}{ Child age (years) } & 713 & $2 \cdot 00$ & $1.97,2.03$ & 1.99 & $1.96,2.03$ \\
\hline \multicolumn{2}{|l|}{ Child BMI Z-score } & 704 & 0.76 & $0.06,1.47$ & 0.79 & $0.12,1.51$ \\
\hline \multicolumn{2}{|l|}{ Food responsiveness $\ddagger$} & 653 & $2 \cdot 2$ & $1 \cdot 8,2 \cdot 6$ & $2 \cdot 2$ & $1 \cdot 8,2 \cdot 6$ \\
\hline \multicolumn{2}{|l|}{ Enjoyment of food $\ddagger$} & 653 & 4.0 & $3 \cdot 5,4 \cdot 3$ & $4 \cdot 0$ & $3 \cdot 5,4 \cdot 3$ \\
\hline \multicolumn{2}{|c|}{ Satiety responsiveness/slowness in eating } & 653 & $3 \cdot 0$ & $2 \cdot 7,3 \cdot 3$ & 3.0 & $2 \cdot 7,3 \cdot 3$ \\
\hline \multicolumn{2}{|c|}{ Food fussinessł } & 653 & $2 \cdot 5$ & $2 \cdot 0,2 \cdot 8$ & 2.5 & $2 \cdot 0,2 \cdot 8$ \\
\hline \multicolumn{2}{|l|}{ Emotional overeating $\ddagger$} & 652 & 1.5 & $1 \cdot 0,2 \cdot 0$ & 1.5 & $1 \cdot 0,2 \cdot 0$ \\
\hline \multicolumn{2}{|l|}{ Emotional undereating } & 653 & 3.0 & $2 \cdot 3,3 \cdot 5$ & $3 \cdot 0$ & $2 \cdot 3,3.5$ \\
\hline \multicolumn{2}{|l|}{ Desire to drink $\ddagger$} & 653 & $2 \cdot 7$ & $2 \cdot 3,3 \cdot 3$ & $2 \cdot 7$ & $2 \cdot 3,3 \cdot 3$ \\
\hline \multicolumn{2}{|c|}{$\%$ El from discretionary food/beverages - total daily } & & $\mathrm{N} / \mathrm{A}$ & & $19 \cdot 6$ & $13 \cdot 2,27 \cdot 8$ \\
\hline \multicolumn{2}{|c|}{$\begin{array}{l}\% \text { El from discretionary food/beverages - main } \\
\text { meals only }\end{array}$} & & $\mathrm{N} / \mathrm{A}$ & & $11 \cdot 7$ & $6 \cdot 7,17 \cdot 8$ \\
\hline \multicolumn{2}{|c|}{$\begin{array}{l}\% \text { El from discretionary food/beverages - snacks } \\
\text { only }\end{array}$} & & $\mathrm{N} / \mathrm{A}$ & & $6 \cdot 5$ & $2 \cdot 9,10 \cdot 8 \dagger \dagger$ \\
\hline \multicolumn{7}{|c|}{ Parental and family variables } \\
\hline \multicolumn{2}{|c|}{ Maternal age (years)§ } & 716 & $31 \cdot 0$ & $28 \cdot 0,35 \cdot 0$ & $32 \cdot 0$ & $28 \cdot 0,35 \cdot 0$ \\
\hline \multicolumn{2}{|l|}{ Maternal BMI $\left(\mathrm{kg} / \mathrm{m}^{2}\right) \|$} & 701 & $24 \cdot 8$ & $22 \cdot 2,28 \cdot 6$ & $24 \cdot 6$ & $22 \cdot 1,28 \cdot 2$ \\
\hline Marital status & Single & 654 & 36 & 6 & 13 & 2 \\
\hline & Partnered & & 618 & 94 & 513 & 98 \\
\hline Maternal education§ & University & 716 & 417 & 58 & 325 & 62 \\
\hline & No university & & 299 & 42 & 201 & 38 \\
\hline Paternal education§ & University & 700 & 298 & 43 & 232 & 44 \\
\hline & No university & & 402 & 57 & 294 & 56 \\
\hline Maternal work hours & Not working & 639 & 275 & 43 & 217 & 41 \\
\hline & 1 to $<21 \mathrm{~h}$ & & 166 & 26 & 146 & 28 \\
\hline & 21 to $<35 \mathrm{~h}$ & & 135 & 21 & 115 & 22 \\
\hline & $35+h$ & & 63 & 10 & 48 & 9 \\
\hline Paternal work hours & Not working & 640 & 26 & 4 & 20 & 4 \\
\hline & 1 to $<35 \mathrm{~h}$ & & 53 & 8 & 54 & 10 \\
\hline & 35 to $40 \mathrm{~h}$ & & 360 & 56 & 301 & 57 \\
\hline & $>40 \mathrm{~h}$ & & 165 & 26 & 138 & 26 \\
\hline & $\mathrm{N} / \mathrm{A}$ & & 36 & 6 & 13 & 2 \\
\hline Household income & Less than $50 \mathrm{k} /$ year & 631 & 113 & 18 & 77 & 15 \\
\hline & $50 \mathrm{k} /$ year or more & & 518 & 82 & 449 & 85 \\
\hline Number of children & One & 634 & 356 & 56 & 289 & 55 \\
\hline & More than one & & 278 & 44 & 237 & 45 \\
\hline Study allocation & NOURISH intervention & 719 & 253 & 35 & 172 & 33 \\
\hline & NOURISH Control & & 279 & 39 & 187 & 36 \\
\hline & SAIDI & & 187 & 26 & 167 & 32 \\
\hline Reward for behaviour* & & 653 & 1.5 & $1 \cdot 3,2 \cdot 3$ & 1.5 & $1 \cdot 3,2 \cdot 3$ \\
\hline Reward for eating ${ }^{* *}$ & & 654 & 1.5 & $1 \cdot 0,2 \cdot 3$ & 1.5 & $1 \cdot 0,2 \cdot 0$ \\
\hline Covert restriction ${ }^{\star *}$ & & 652 & 3.3 & $2 \cdot 5,3 \cdot 8$ & 3.3 & $2 \cdot 5,3 \cdot 8$ \\
\hline Overt restriction** & & 653 & 3.5 & $2 \cdot 8,4 \cdot 0$ & 3.5 & $2 \cdot 8,4 \cdot 0$ \\
\hline Same food ${ }^{* *}$ & & 652 & $5 \cdot 0$ & $3 \cdot 0,5 \cdot 0$ & $5 \cdot 0$ & $3 \cdot 0,5 \cdot 0$ \\
\hline
\end{tabular}

IQR, interquartile range; El, energy intake; N/A, dietary data not available; SAIDI, South Australian Infants Dietary Intake.

*Sample size varies between $n 631$ and $n 719$ due to missing data, with $n 719$ providing some data at 2-year data collection, of which 654 provided survey data.

tRegression sample includes imputed missing data.

¥Child Eating Behaviour Questionnaire ${ }^{(15)}$ sub-scales - scores from 1 to 5, with higher scores indicating more of the behaviour.

$\S$ Data collected at recruitment/child birth.

||Data collected at time 1/child aged 4-6 months.

IIncludes $n 1$ father, who became primary carer before T3 measurements (all other maternal data are from the mother at earlier time points).

${ }^{\star \star}$ Food Parenting and Structure Questionnaire ${ }^{(40)}$ sub-scales/items - score between 1 and 5 , with higher scores indicating more of the parenting practice.

$\dagger † n 525$ participants as one child was considered a 'non-consumer' of snacks.

found for main meals, where children with fathers that had a university education consumed more energy from discretionary foods and beverages at snacks than children with fathers without a university education $(\beta=0 \cdot 12$, $P=0.01)$. Of the remaining covariates, covert restriction was found to be the most important determinant of children's discretionary food and beverage intake across all three models $(\beta=-0 \cdot 16, P<0 \cdot 001 ; \beta=-0 \cdot 14, P=0.001$ and $\beta=-0 \cdot 14, P=0.003$, respectively). Children whose mothers reported using more covert restriction practices consumed a lower total proportion of energy from discretionary foods and beverages, and a lower proportion at main meals and snacks.

Overall, the models accounted for $11.7 \%$ of the variance in children's total discretionary food and beverage intake $\left(R^{2}=0.117, P<0.001\right), 11.4 \%$ in discretionary food and 


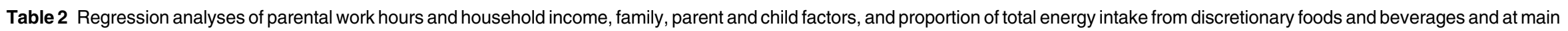
meals and snacks, in 2-year-old Australian children

\begin{tabular}{|c|c|c|c|c|c|c|c|c|c|c|c|}
\hline \multirow{2}{*}{\multicolumn{2}{|c|}{ Step $†$}} & \multirow[b]{2}{*}{ Variable } & \multicolumn{3}{|c|}{$\begin{array}{c}\% \text { Daily energy from } \\
\text { discretionary food/bevs } \\
(n 526)\end{array}$} & \multicolumn{3}{|c|}{$\begin{array}{l}\% \text { Daily energy from } \\
\text { discretionary food/bevs } \\
\text { consumed at main meals } \\
(n 526)\end{array}$} & \multicolumn{3}{|c|}{$\begin{array}{c}\% \text { Daily energy from dis- } \\
\text { cretionary food/bevs } \\
\text { consumed at snacks } \\
(n 525) \ddagger\end{array}$} \\
\hline & & & $\beta$ & SE & $\beta$ & $\beta$ & SE & $\beta$ & $\beta$ & SE & $\beta$ \\
\hline \multirow{8}{*}{1} & \multirow{8}{*}{ Parental work hours and household income } & Maternal working hours (ref: not working) & & & & & & & & & \\
\hline & & 1 to $<21 \mathrm{~h}$ & 0.86 & $1 \cdot 14$ & 0.04 & 0.19 & 0.86 & 0.01 & 0.83 & 0.65 & 0.06 \\
\hline & & 21 to $<35 \mathrm{~h}$ & $2 \cdot 81$ & 1.29 & $0.11^{*}$ & 2.04 & 0.98 & $0 \cdot 10^{\star}$ & 0.67 & 0.74 & 0.05 \\
\hline & & $\begin{array}{l}35+\mathrm{h} \\
\text { Paternal working hours (ref: } 35 \text { to } 40 \mathrm{~h} \text { ) }\end{array}$ & -0.74 & 1.74 & -0.02 & -0.16 & 1.33 & -0.01 & -0.53 & 1.00 & -0.03 \\
\hline & & Not working & -1.74 & 2.49 & -0.03 & 0.69 & 1.90 & 0.02 & $-2 \cdot 84$ & 1.43 & $-0.09^{*}$ \\
\hline & & 1 to $<35 \mathrm{~h}$ & -0.56 & 1.60 & -0.02 & $-1 \cdot 12$ & $1 \cdot 21$ & -0.04 & -0.01 & 0.91 & -0.00 \\
\hline & & $>40 \mathrm{~h}$ & -1.96 & 1.07 & -0.08 & $-2 \cdot 11$ & 0.81 & $-0 \cdot 11^{*}$ & -0.26 & 0.61 & -0.02 \\
\hline & & Household income (ref: $<50 \mathrm{k}$ ) & -4.60 & 1.47 & $-0 \cdot 15^{\star \star}$ & -2.69 & $1 \cdot 12$ & $-0 \cdot 12^{*}$ & $-2 \cdot 16$ & 0.84 & $-0 \cdot 13^{\star}$ \\
\hline \multirow[t]{3}{*}{2} & Household factors & Partnered (ref: single) & 3.15 & 3.14 & 0.05 & 3.33 & 2.39 & 0.06 & -0.00 & 1.79 & 0.00 \\
\hline & & Paternal education (ref: no university)§ & -0.82 & 1.01 & -0.04 & -1.93 & 0.77 & $-0 \cdot 12^{*}$ & 1.44 & 0.58 & $0.12^{*}$ \\
\hline & & No of children (ref: one child) & 1.11 & 1.03 & 0.05 & 1.22 & 0.79 & 0.07 & 0.08 & 0.59 & 0.01 \\
\hline \multirow[t]{3}{*}{3} & Maternal factors & Maternal education (ref: no university)§ & -1.41 & 1.05 & -0.06 & $-1 \cdot 10$ & 0.80 & -0.07 & -0.41 & 0.60 & -0.03 \\
\hline & & Maternal age§ & -0.07 & 0.10 & -0.03 & -0.06 & 0.08 & -0.03 & -0.04 & 0.06 & -0.03 \\
\hline & & Maternal BMI $\|$ & 0.06 & 0.09 & 0.03 & 0.06 & 0.07 & 0.04 & 0.02 & 0.05 & 0.02 \\
\hline \multirow[t]{6}{*}{4} & Parental feeding practices & Reward for behaviour & 1.63 & 0.85 & 0.10 & 0.82 & 0.65 & 0.07 & 0.73 & 0.49 & 0.08 \\
\hline & & Reward for eating & 1.77 & 0.77 & $0.12^{*}$ & 1.35 & 0.58 & $0.12^{*}$ & 0.28 & 0.44 & 0.04 \\
\hline & & Covert restriction & -2.00 & 0.54 & $-0 \cdot 16^{\star \star \star}$ & -1.33 & 0.41 & $-0 \cdot 14^{* *}$ & -0.94 & 0.31 & $-0 \cdot 14^{\star \star}$ \\
\hline & & Overt restriction & -0.49 & 0.56 & -0.04 & -0.31 & 0.43 & -0.03 & -0.34 & 0.32 & -0.05 \\
\hline & & Same food & 0.06 & 0.44 & 0.01 & -0.41 & 0.33 & -0.06 & 0.44 & 0.25 & 0.09 \\
\hline & & Group allocation (ref: NOURISH control/SAIDI) & -1.30 & 1.04 & -0.06 & -1.03 & 0.79 & -0.06 & -0.81 & 0.59 & -0.06 \\
\hline \multirow[t]{3}{*}{5} & Child factors & Child gender (ref: male) & 1.10 & 0.92 & 0.05 & 0.40 & 0.70 & 0.02 & 0.68 & 0.53 & 0.06 \\
\hline & & Child age & -1.76 & 8.29 & -0.01 & 1.57 & $6 \cdot 30$ & 0.01 & $-3 \cdot 21$ & 4.74 & -0.03 \\
\hline & & Child BMl Z-score & -0.72 & 0.47 & -0.07 & -0.70 & 0.36 & -0.09 & $-0 \cdot 18$ & 0.27 & -0.03 \\
\hline \multirow[t]{7}{*}{6} & Child eating behaviours & Food responsiveness & -0.38 & 0.96 & -0.02 & -0.14 & 0.73 & -0.01 & -0.20 & 0.55 & -0.02 \\
\hline & & Enjoyment of food & 0.09 & 1.14 & 0.01 & 0.18 & 0.86 & 0.01 & 0.30 & 0.65 & 0.03 \\
\hline & & Satiety and slowness & 2.47 & 1.11 & $0.12^{*}$ & 1.82 & 0.84 & $0.12^{*}$ & 0.67 & 0.63 & 0.06 \\
\hline & & Food fussiness & -0.24 & 0.93 & -0.02 & -0.70 & 0.70 & -0.06 & 0.81 & 0.53 & 0.09 \\
\hline & & Emotional overeating & 1.75 & 1.13 & 0.08 & 0.99 & 0.86 & 0.06 & 0.68 & 0.65 & 0.06 \\
\hline & & Emotional undereating & $-1 \cdot 11$ & 0.58 & -0.09 & -1.01 & 0.44 & $-0 \cdot 11^{*}$ & 0.16 & 0.34 & 0.02 \\
\hline & & Desire to drink & -0.16 & 0.58 & -0.01 & -0.17 & 0.44 & -0.02 & -0.03 & 0.33 & -0.00 \\
\hline \multicolumn{2}{|c|}{ Adjusted $R^{2}$} & & & \multicolumn{2}{|c|}{$0.117^{\star \star *}$} & & \multicolumn{2}{|c|}{$0.114^{* \star *}$} & \multicolumn{3}{|c|}{0.052} \\
\hline
\end{tabular}

Ref, reference category; SAIDI, South Australian Infants Dietary Intake.

${ }^{*} P<005$.

†Only the final results of the hierarchical models are displayed.

$\neq n 1$ participant excluded as they were considered a non-consumer of snacks.

§At recruitment/child birth.

$\|$ At Time $1 /$ child aged $4-6$ months.

$x * \pm<001$. 
beverage intake at main meals $\left(R^{2}=0.114, P<0.001\right)$ and $5.2 \%$ at snacks $\left(R^{2}=0.052, P=0.002\right)$. The majority of variance was accounted for by the parental work hours and household income (Step 1) and primary carer parenting (Step 4) steps of the regressions (see online supplementary material, Supplemental Tables 1-3).

\section{Discussion}

This study explored parental work hours and household income as opportunity-related determinants of discretionary food and beverage intake in young Australian children and investigated differential associations across eating occasions. Household income had a strong, inverse association with children's discretionary food and beverage intake across all eating occasions. Maternal and paternal work hours were also key determinants of young children's discretionary food and beverage intake. Maternal work hours had a non-linear relationship with young children's discretionary food and beverage intake at main meals, with children of mothers working 21-35 h/week consuming more than those of mothers who were not working, whereas children of fathers working more than $40 \mathrm{~h} /$ week had a lower intake of discretionary foods and beverages at main meals compared with those working 35-40 h, and children of fathers who were not working consumed less at snacks. These findings suggest that intervention strategies addressing young children's intake of discretionary foods and beverages should consider opportunity-related determinants of intake such as maternal and paternal time and money and may benefit from tailoring according to eating occasion.

\section{Housebold income}

Consistent with prior research, household income was inversely associated with children's discretionary food and beverage intake in all three models ${ }^{(7,46)}$. Children from households with an income of less than $\$ 50000$ AUD/year (i.e. the bottom two quintiles for gross household income in Australia in 2015-2016 ${ }^{(37)}$ ) consumed around $4.6 \%$ more energy from discretionary foods and beverages than those from households with an income of $\$ 50000$ AUD or more. Both measurable income and 'feeling poor' have been associated with dietary intake in adults, with the effect being stronger with persisting scarcity ${ }^{(24)}$. The mechanisms of this relationship are complex, being that there is no substantial difference between the cost of healthy and unhealthy diets ${ }^{(47)}$. The cost of diets in line with the dietary guidelines is between 88 and $99 \%$ of the cost of current, unhealthy diets in Australian families ${ }^{(47)}$. Similarly in some populations in New Zealand, such as those with a higher energy intake, the cost of a healthy diet is lower than that of current diets ${ }^{(48)}$. Furthermore, modelling has shown that even when time cost is taken into account, healthier home-assembled and home-made meals were generally cheaper than takeaway meals ${ }^{(49)}$. However, families with a low disposable income may be driven to serve acceptable foods that are not rejected and wasted, such as palatable and shelf-stable discretionary foods and beverages ${ }^{(30)}$. A low disposable income may also act as a barrier to the purchase of other tools supporting healthy food preparation, such as healthy pre-prepared meals and cooking equipment. Regardless of the mechanism, this research shows that household income is an important opportunity-related determinant of children's discretionary food and beverage intake and must be considered when planning interventions or policy strategies to address intake.

\section{Parental work bours}

Both maternal and paternal work hours were associated with young children's intake of energy from discretionary foods and beverages. Children with mothers working 21$35 \mathrm{~h} /$ week consumed on average $2 \cdot 8 \%$ more energy from discretionary foods and beverages daily than children with mothers who worked up to $21 \mathrm{~h} /$ week, full time $(35+$ $\mathrm{h} /$ week) or were not working. Research in preschool and school-age children has found that greater maternal work hours are associated with lower dietary quality ${ }^{(50,51)}$. This may be through the impact of work hours on time available for food-related behaviour such as shopping, cooking and eating with children ${ }^{(52)}$. In US school-age children, a 20-h increase in maternal work hours was associated with an increased likelihood of consuming fast food at least once per week and consuming sugar-sweetened beverages at least once per day ${ }^{(50)}$. Similarly in a study of multiple European countries, full-time maternal employment was found to be negatively associated with children's diet quality, although the effect was relatively small ${ }^{(51)}$. The inclusion of a broad range of parent and child covariates, and the younger age of our sample may account for the difference in findings of the present work.

The inclusion of paternal work hours in this study was unique, with prior research not generally accounting for this factor ${ }^{(26,38,53)}$. Fathers work time has tended to be viewed as unimportant in public policy related to parenting, despite their important role in contributing key family resources such as time and money ${ }^{(54)}$. Children with fathers working greater than $40 \mathrm{~h} /$ week consumed less energy in the form of discretionary foods and beverages at main meals, while children of fathers who were not working consumed less at snacks. Although mothers are more frequently the primary caregiver and food provider in Australian households ${ }^{(55)}$, these findings are a reminder that the father or father figure is also a key influencer of young children's discretionary food and beverage intake ${ }^{(56)}$. Whether this is through their direct contribution to food-related tasks or role modelling, or the provision of support to the primary food provider ${ }^{(57)}$ or through the increased use of external supports such as childcare 
and/or extended family, the mechanism underlying these findings is unclear and warrants further investigation.

There is no simple explanation for the non-linear findings of this study in relation to maternal and paternal work hours. Past research has similarly demonstrated nonlinear relationships between parental work hours and weight and weight-related behaviours ${ }^{(26,38,53)}$. One possible explanation may be that low maternal work hours allow more opportunity for food-related processes, whilst full-time maternal and/or paternal work hours may necessitate a level of organisation and flexibility regarding food-related processes that offer some protection. For example, women working full-time may seek external support with food provision, or outsource other household tasks such as cleaning to allow more time for food provision ${ }^{(58)}$. Furthermore, the enrichment that full-time employment may add to maternal and paternal capability, for example, may outweigh negative effects on time availability for food provision ${ }^{(26)}$. However, these relationships may not be due to the effect of work hours on time available for food provision at all and may not be causal. More research, including qualitative research, is needed to understand if these relationships are due to the availability or scarcity of time, or some other mechanism, such as self-efficacy.

The relationship between children's discretionary food and beverage intake and parental work hours varied by eating occasion. Both maternal and paternal work hours were associated with children's intake of discretionary foods and beverages at main meals, whilst only paternal work hours were important at snacks. Main meals require more planning and preparation than snacks; thus, work hours may be a more important determinant of children's discretionary food and beverage intake at main meals compared with snacks. Horning et $a l^{(59)}$, in their work investigating mainly mothers' reasons for purchasing packaged, processed meals, found that those who worked more hours were more likely to report time scarcity as a reason for purchasing convenience foods. By contrast, a discrete choice experiment with mainly mothers of children aged 3-7 years found that time was not a significant factor influencing parental snack choice when weighed up against child acceptance or resistance, co-parent support and home food availability ${ }^{(31)}$. This suggests that different intervention approaches may be required at different eating occasions, with time constraints possibly being more relevant when targeting main meals.

\section{Covert restriction}

Of the covariates, the parental feeding practices step resulted in the largest increase in variance for all models owing to the parental feeding practice 'covert restriction', while child factors such as gender, age, BMI $Z$-score and eating behaviour were less important in this age group. Covert restriction is the act of restricting a child's food environment so that they are unaware of it; for example, by avoiding the purchase of discretionary foods and beverages ${ }^{(60)}$. This contrasts with overt restriction which includes more direct control and restriction of child intake ${ }^{(25,60)}$. Similar work in children of various ages confirms the importance of covert restriction in limiting discretionary food and beverage intake ${ }^{(25,61)}$. This highlights the importance of targeting parental capability with respect to setting up a healthy home food environment, particularly in families with young children.

\section{Strengths and limitations}

The incorporation of both maternal and paternal factors was a key strength of this work, as it recognises the influence of both parents on children's dietary intake, whilst the inclusion of a broad range of covariates ensured that key parent and child factors were adjusted for. This research was however limited by the use of work hours as a proxy for time available for food provision, as work hours do not take into account time commitments outside of work and when and where work takes place (e.g. shift work and working from home). Furthermore, this economic perspective of time does not address the perception of time scarcity, which has been identified as equally important as measurable time ${ }^{(24)}$. Similarly, gross household income does not take into account the availability of money for food and food-related purchases after tax and other essential expenses such as mortgage repayments or rent. Nor does it consider self-assessed poorness, which has been shown to be associated with an increased likelihood of consuming energy from discretionary foods and beverages in adults ${ }^{(24)}$.

As with similar community-based obesity prevention studies $^{(19)}$, NOURISH parents were older, of a higher education and more likely to be partnered than the broader population ${ }^{(22)}$. This may explain the lower discretionary food and beverage intake, $20 \%$ in this sample of children compared with $30 \%$ in 2-3-year-olds in the Australian Health Survey ${ }^{(62)}$. The use of parent-reported 24-h food recalls and records was a strength of this work; however, these measures are prone to social desirability bias leading to possible underreporting of children's discretionary food and beverage intake ${ }^{(63)}$. Finally, the amount of variance explained by the models was relatively small, although of a similar magnitude to a study investigating home environment determinants of intake in school-age children (9 and $16 \%$ for sweet and savoury snacks and high-energy beverages, respectively) ${ }^{(64)}$. Although child, parent and household factors were demonstrated to be important in the present work, there are clearly other determinants at play that were not captured. For example, home food environment factors such as food availability and parent intake $^{(65)}$, local food environment factors such as supermarkets, food outlets and childcare centres, and foodrelated policy such as those influencing food pricing and 
marketing $^{(10)}$ were not included or adjusted for in the analysis.

\section{Recommendations for future research}

Future research in this space would benefit from the inclusion of variables that better represent time and income availability and feelings of scarcity in families of young children, and the use of more socio-economically diverse samples. Analyses that allow the investigation of pathways and interactions between maternal and paternal work hours, and work hours and income, may support a deeper understanding of the interplay between time and money. Intervention development should consider strategies that enable behaviour by increasing means or reducing barriers, by restructuring the physical or social environment or by imparting skills, as these are thought to be effective in addressing opportunity-related determinants of behaviour such as time and money ${ }^{(18)}$, although care must be taken to ensure that interventions and programmes are widely accessible and do not increase social inequities between those who can afford or access support and those who cannot $^{(58)}$

\section{Conclusion}

This investigation of opportunity-related determinants of young children's discretionary food and beverage intake through a novel eating occasions lens has provided evidence that can be used to enhance future interventions. Parental work hours and household income were found to be key determinants of young children's discretionary food and beverage intake, along with parental factors such as covert restriction. Household income was a strong and consistent determinant of children's discretionary food and beverage intake across all eating occasions, meaning that intervention and policy strategies targeting discretionary food and beverage intake in young children should consider the financial implications of dietary change. The maternal work profile of 21-35 h/week was associated with greater child intake of discretionary foods and beverages at main meals, suggesting that this group may require more support to manage the competing demands of work, caregiving and domestic duties, such as evening meal preparation. However, amongst an increasing body of research considering the role of fathers (or father figures) in shaping children's food intake and preferences ${ }^{(66,67)}$, this study also suggests a need to consider fathers and other parents or caregivers in future dietary interventions.

\section{Acknowledgements}

Acknowledgements: Participants of NOURISH and SAIDI. Financial support: CEM was supported by an Australian
Government Research Training Program Scholarship, National Health and Medical Research Council postgraduate scholarship (1114194), a top-up scholarship funded by Flinders University and The Early Prevention of Obesity in Childhood Centre for Research Excellence (1101675), and a King and Amy O'Malley Trust Postgraduate Scholarship. R.A.L., R.B. and R.K.G. are researchers within the NHMRC Centre for Research Excellence in The Early Prevention of Obesity in Childhood (1101675). Conflicts of interest: There are no conflicts of interest. Authorship: C.E.M. led the conception and design of the study, under the guidance of T.P.W., L.K.B., R.A.L. and R.K.G., and in consultation with R.B. C.E.M. prepared the data and conducted the analyses, with all co-authors contributing to the interpretation of results. C.E.M. drafted the manuscript, with all co-authors critically reviewing drafts and reading and approving of the final manuscript. Ethics of buman subject participation: This study was conducted according to the guidelines laid down in the Declaration of Helsinki and all procedures involving research study participants were approved by the Flinders University and Queensland University of Technology Human Research Ethics Committees, and Human Research Ethics Committee's for each recruitment hospital. Written informed consent was obtained from all subjects/patients.

\section{Supplementary material}

For supplementary material accompanying this paper visit https://doi.org/10.1017/S1368980022000349

\section{References}

1. Australian Institute of Health and Welfare (2018) Nutrition Across the Life Stages. Canberra: Australian Government.

2. Krebs-Smith SM, Guenther PM, Subar AF et al. (2010) Americans do not meet federal dietary recommendations. J Nutr 140, 1832-1838.

3. Public Health England \& National Diet and Nutrition Survey (2019) Results from Years 7 and 8 (Combined) of the Rolling Programme (2014/2015 to 2015/2016). UK: Public Health England.

4. World Health Organization (2018) Noncommunicable Diseases Country Profiles 2018. Geneva: World Health Organization.

5. National Health \& Medical Research Council (2013) Australian Dietary Guidelines - Educator Guide. Canberra: Australian Government.

6. Fayet-Moore F, McConnell A, Cassettari T et al. (2019) Discretionary intake among Australian adults: prevalence of intake, top food groups, time of consumption and its association with sociodemographic, lifestyle and adiposity measures. Public Health Nutr 22, 1-14.

7. Spence AC, Campbell KJ, Lioret S et al. (2018) Early childhood vegetable, fruit, and discretionary food intakes do not meet dietary guidelines, but do show socioeconomic differences and tracking over time. J Acad Nutr Diet 118, $1634-1643$. 
8. Birch LL \& Doub AE (2014) Learning to eat: birth to age 2 years. Am J Clin Nutr 99, 723S-728S.

9. Zarnowiecki DM, Dollman J \& Parlette N (2014) Associations between predictors of children's dietary intake and socioeconomic position: a systematic review of the literature. Obes Rev 15, 375-391.

10. Rosenkranz RR \& Dzewaltowski DA (2008) Model of the home food environment pertaining to childhood obesity. Nutr Rev 66, 123-140.

11. Vaughn AE, Ward DS, Fisher JO et al. (2016) Fundamental constructs in food parenting practices: a content map to guide future research. Nutr Rev 74, 98-117.

12. Birch LL \& Fisher JO (1998) Development of eating behaviors among children and adolescents. Pediatrics 101, 539-549.

13. Birch LL (1999) Development of food preferences. Annu Rev Nutr 19, 41-62.

14. Daniels LA (2019) Feeding practices and parenting: a pathway to child health and family happiness. Ann Nutr Metab 74, Suppl. 2, 29-42.

15. Wardle J, Guthrie CA, Sanderson S et al. (2001) Development of the children's eating behaviour questionnaire. J Child Psychol Psychiatry 42, 963-970.

16. Pearson N, Biddle SJH \& Gorely T (2009) Family correlates of fruit and vegetable consumption in children and adolescents: a systematic review. Public Health Nutr 12, 267-283.

17. Golley RK, Hendrie GA, Slater A et al. (2011) Interventions that involve parents to improve children's weight-related nutrition intake and activity patterns - what nutrition and activity targets and behaviour change techniques are associated with intervention effectiveness? Obes Rev 12, 114-130.

18. Michie S, van Stralen MM \& West R (2011) The behaviour change wheel: a new method for characterising and designing behaviour change interventions. Implement Sci $\mathbf{6}, 42$.

19. Campbell KJ, Lioret S, McNaughton SA et al. (2013) A parentfocused intervention to reduce infant obesity risk behaviors: a randomized trial. Pediatrics 131, 652-660.

20. Döring N, Ghaderi A, Bohman B et al. (2016) Motivational interviewing to prevent childhood obesity: a cluster RCT. Pediatrics 137, e20153104.

21. Johnson BJ, Zarnowiecki D, Hendrie GA et al. (2018) How to reduce parental provision of unhealthy foods to 3- to 8-yearold children in the home environment? A systematic review utilizing the behaviour change wheel framework. Obes Rev 19, 1359-1370.

22. Magarey A, Mauch C, Mallan K et al. (2016) Child dietary and eating behavior outcomes up to 3.5 years after an early feeding intervention: the NOURISH RCT. Obesity 24, 1537-1545.

23. Wen LM, Baur LA, Simpson JM et al. (2015) Sustainability of effects of an early childhood obesity prevention trial over time: a further 3-year follow-up of the healthy beginnings trial. JAMA Pediatr 169, 543-551.

24. Venn D \& Strazdins L (2017) Your money or your time? How both types of scarcity matter to physical activity and healthy eating. Soc Sci Med 172, 98-106.

25. Zarnowiecki DM, Parletta N \& Dollman J (2016) Socio-economic position as a moderator of 9-13-year-old children's non-core food intake. Public Health Nutr 19, 55-70.

26. Li J, Akaliyski P, Schafer J et al. (2017) Non-linear relationship between maternal work hours and child body weight: evidence from the western Australian pregnancy cohort (Raine) study. Soc Sci Med 186, 52-60.

27. Fayet-Moore F, Peters V, McConnell A et al. (2017) Weekday snacking prevalence, frequency, and energy contribution have increased while foods consumed during snacking have shifted among Australian children and adolescents: 1995, 2007 and 2011-2012 National Nutrition Surveys. Nutr J 16, 65.

28. Sui Z, Raubenheimer D \& Rangan A (2017) Exploratory analysis of meal composition in Australia: meat and accompanying foods. Public Health Nutr 20, 2157-2165.
29. Jabs J, Devine CM, Bisogni CA et al. (2007) Trying to find the quickest way: employed mothers' constructions of time for food. J Nutr Educ Behav 39, 18-25.

30. Pescud M \& Pettigrew S (2014) 'I know it's wrong, but ... ': a qualitative investigation of low-income parents' feelings of guilt about their child-feeding practices. Matern Child Nutr 10, 422-435.

31. Johnson BJ, Golley RK, Zarnowiecki D et al. (2020) Understanding the influence of physical resources and social supports on primary food providers' snack food provision: a discrete choice experiment. Int J Behav Nutr Phys Act 17, 155

32. Lachat C, Hawwash D, Ocke MC et al. (2016) Strengthening the reporting of observational studies in epidemiology-nutritional epidemiology (STROBE-nut): an extension of the STROBE statement. PLoS Med 13, e1002036.

33. Daniels LA, Magarey A, Battistutta D et al. (2009) The NOURISH randomised control trial: positive feeding practices and food preferences in early childhood - a primary prevention program for childhood obesity. BMC Public Health 9, 387.

34. WHO Multicentre Growth Reference Study Group (2006) WHO Child Growth Standards: Length/Height-for-Age, Weight-for-Age, Weight-for-Length, Weight-for-Height and Body Mass Index-for-Age: Methods and Development. https://www.who.int/childgrowth/standards/technical_ report/en/ (accessed July 2020).

35. Daniels LA, Mallan KM, Nicholson JM et al. (2015) An early feeding practices intervention for obesity prevention. Pediatrics 136, e40-e49.

36. Burrows TL, Martin RJ \& Collins CE (2010) A systematic review of the validity of dietary assessment methods in children when compared with the method of doubly labeled water. J Am Diet Assoc 110, 1501-1510.

37. Australian Bureau of Statistics (2017) 6523.0 - Household Income and Wealth, Australia, 2015-2016. Canberra: Australian Government.

38. Brown JE, Broom DH, Nicholson JM et al. (2010) Do working mothers raise couch potato kids? Maternal employment and children's lifestyle behaviours and weight in early childhood. Soc Sci Med 70, 1816-1824.

39. Mallan KM, Liu WH, Mehta RJ et al. (2013) Maternal report of young children's eating styles. Validation of the children's eating behaviour questionnaire in three ethnically diverse Australian samples. Appetite 64, 48-55.

40. Jansen E, Mallan KM, Nicholson JM et al. (2014) The feeding practices and structure questionnaire: construction and initial validation in a sample of Australian first-time mothers and their 2-year olds. Int J Behav Nutr Phys Act 11, 72.

41. Food Standards Australia New Zealand (2008) AUSNUT 2007 - Australian Food Supplement and Nutrient Database for Estimation of Population Nutrient Intakes. Canberra: Australian Government Publishing Service.

42. Australian Bureau of Statistics (2014) Australian Health Survey - Discretionary Food List. https://www.abs.gov.au/ AUSSTATS/abs@.nsf/DetailsPage/4363.0.55.0012011-13? OpenDocument (accessed July 2020).

43. Leech RM, Worsley A, Timperio A et al. (2015) Characterizing eating patterns: a comparison of eating occasion definitions. Am J Clin Nutr 102, 1229-1337.

44. Austin PC \& Steyerberg EW (2015) The number of subjects per variable required in linear regression analyses. $J$ Clin Epidemiol 68, 627-636.

45. Daniels LA, Mallan KM, Battistutta D et al. (2014) Child eating behavior outcomes of an early feeding intervention to reduce risk indicators for child obesity: the NOURISH RCT. Obesity 22, E104-E111.

46. Zarnowiecki D, Ball K, Parletta N et al. (2014) Describing socioeconomic gradients in children's diets - does the 
socioeconomic indicator used matter? Int J Behav Nutr Phys Act 11, 44 .

47. Lee AJ, Kane S, Ramsey R et al. (2016) Testing the price and affordability of healthy and current (unhealthy) diets and the potential impacts of policy change in Australia. BMC Public Health 16, 315.

48. Vandevijvere S, Young N, Mackay S et al. (2018) Modelling the cost differential between healthy and current diets: the New Zealand case study. Int J Behav Nutr Phys Act 15, 16.

49. Mackay S, Vandevijvere S, Xie P et al. (2017) Paying for convenience: comparing the cost of takeaway meals with their healthier home-cooked counterparts in New Zealand. Public Health Nutr 20, 2269-2276.

50. Datar A, Nicosia N \& Shier V (2014) Maternal work and children's diet, activity, and obesity. So Sci Med 107, 196-204.

51. Gwozdz W, Sousa-Poza A, Reisch LA et al. (2013) Maternal employment and childhood obesity - a European perspective. I Health Econ 32, 728-742.

52. Cawley J \& Liu F (2012) Maternal employment and childhood obesity: a search for mechanisms in time use data. Econ Hum Biol 10, 352-364.

53. Burnett AJ, Worsley A, Lacy KE et al. (2019) Moderation of associations between maternal parenting styles and Australian pre-school children's dietary intake by family structure and mother's employment status. Public Health Nutr 22, 1-13.

54. Strazdins L, Baxter JA \& Li J (2017) Long hours and longings: Australian children's views of fathers' work and family time. J Marriage Fam 79, 965-982.

55. Burton M, Reid M, Worsley A et al. (2017) Food skills confidence and household gatekeepers' dietary practices. Appetite 108, 183-190.

56. Walsh AD, Cameron AJ, Hesketh KD et al. (2015) Associations between dietary intakes of first-time fathers and their 20-month-old children are moderated by fathers' BMI, education and age. Br J Nutr 114, 988-994.

57. Jansen E, Harris H \& Rossi T (2020) Fathers' perceptions of their role in family mealtimes: a grounded theory study. J Nutr Educ Behav 52, 45-54.
58. Craig L, Perales F, Vidal S et al. (2016) Domestic outsourcing, housework time, and subjective time pressure: new insights from longitudinal data. J Marriage Fam 78, 1224-1236.

59. Horning ML, Fulkerson JA, Friend SE et al. (2017) Reasons parents buy prepackaged, processed meals: it is more complicated than "i don't have time". J Nutr Educ Behav 49, 60.e1-66.e1.

60. Jansen E, Williams KE, Mallan KM et al. (2016) The feeding practices and structure questionnaire (FPSQ-28): a parsimonious version validated for longitudinal use from 2 to 5 years. Appetite 100, 172-180.

61. Boots SB, Tiggemann M, Corsini N et al. (2015) Managing young children's snack food intake. The role of parenting style and feeding strategies. Appetite $\mathbf{9 2}, 94-101$.

62. Australian Bureau of Statistics (2014) 4364.0.55.007 Australian Health Survey: Nutrition First Results - Foods and Nutrients, 2011-2012. Canberra: Australian Government.

63. Rangan A, Allman-Farinelli M, Donohoe E et al. (2014) Misreporting of energy intake in the 2007 Australian children's survey: differences in the reporting of food types between plausible, under- and over-reporters of energy intake. J Hum Nutr Diet 27, 450-458.

64. Couch SC, Glanz K, Zhou C et al. (2014) Home food environment in relation to children's diet quality and weight status. J Acad Nutr Diet 114, 1569.e1-1579.e1.

65. Wyse R, Campbell E \& Wolfenden L (2011) Associations between characteristics of the home food environment and fruit and vegetable intake in preschool children: a cross-sectional study. BMC Public Health 11, 938.

66. Walsh AD, Cameron AJ, Crawford D et al. (2016) Dietary associations of fathers and their children between the ages of 20 months and 5 years. Public Health Nutr 19, 2033-2039.

67. Williams A, de Vlieger N, Young M et al. (2018) Dietary outcomes of overweight fathers and their children in the healthy dads, healthy kids community randomised controlled trial. J Hum Nutr Diet 31, 523-532. 